\title{
Anticipated Impact of In-Car Mobile Calls on the Electromagnetic Interaction of Handset Antenna and Human
}

\author{
Salah I. Yahya \\ Department of Software Engineering, Faculty of Engineering, Koya University \\ University Park, Danielle Mitterrand Boulevard, Koya KOY45, Kurdistan Region - F.R. Iraq
}

\begin{abstract}
This paper investigates the impact of the in-car mobile call on the electromagnetic interaction of the mobile handset antenna and user's head. This impact was evaluated from two different perspectives; First, the antenna performance, e.g., total isotropic sensitivity and total efficiency, and second, the specific absorption rate (SAR) induced in the user's head. A YeeFDTD based electromagnetic solver was used to simulate a mobile phone in hand close proximity to head at cheek and tilt positions, and working at a frequency of $1900 \mathrm{MHz}$ (GSM 1900/PCS) while making a call inside a car. A Specific Anthropomorphic Mannequin (SAM) was used to simulate the user's head, a generic phone was used to simulate the mobile phone, a semi-realistic model with three tissues, i.e., skin, bone and muscle, was used to simulate the user's hand, and a CAD model of Ferrari F430-brand was used to simulate the car. The results showed a considerable degradation in the mobile phone antenna performance while making a mobile phone call inside a car that may drive the mobile phone increases its radiated power to establish a successful connection with the base-station antenna, and consequently increases the induced specific absorption rate in the user's head.
\end{abstract}

Index Terms-Antenna efficiency, FDTD, mobile phone antenna, phantom, specific absorption rate (SAR), specific anthropomorphic mannequin (SAM), TIS.

\section{INTRODUCTION}

The possible health hazard of cellular communication handsets due to their electromagnetic (EM) interaction with human have been investigated during the last twenty years, (Toftgard, Hornsleth, and Andersen, 1993; Dimbylow and Mann, 1994; Gandhi, Lazzi and Furse, 1996; Watanabe, et al., 1996; Abousetta, et al., 1999; Francavilla, et al., 2001; Wang

\footnotetext{
ARO-The Scientific Journal of Koya University

Volume II, No 2(2014), Article ID: ARO.10045, 10 pages

DOI: $10.14500 /$ aro. 10045

Received 30 June 2014 ; Accepted 15 September 2014

Regular research paper: Published 17 September 2014

Corresponding author's e-mail: salah.ismaeel@koyauniversity.org

Copyright (c) 2014 Salah I. Yahya. This is an open access article distributed under the Creative Commons Attribution License.
}

and Fujiwara, 2003; Chavannes, et al., 2006; Kouveliotis, et al., 2006; Futter, et al., 2008; Al-Mously and Abousetta, 2008a; Al-Mously and Abousetta, 2008b; Al-Mously and Abousetta, 2008c; Al-Mously and Abdalla, 2009; Al-Mously and Abousetta, 2009a; Al-Mously and Abousetta, 2009b; AlMously, 2011a; Al-Mously, 2011b; Al-Mously, 2012a; AlMously, 2012b). This hazard is varied based on position of handset with respect to user's head and also the hand position that holding the handset. Beside this hazard, a degradation in the handset antenna performance, i.e., total isotropic sensitivity $(T I S)$ and total efficiency $\left(\eta_{\text {tot }}\right)$ are expected and may lead to a low handset antenna power radiation in some circumstances. Consequently, the handset increases the radiated power to maintain a successful call that will certainly increase the specific absorption rate (SAR) induced in the user's head and then increases the radiation hazard.

The influence of the metallic structures of a car body frame on the SAR produced by a cell phone when a complete human body model is placed at different locations inside the vehicle was analyzed by Anzaldi, et al. (2007). A dipole antenna at $835 \mathrm{MHz}$ located as a hands-free communication device was modeled to simulate the mobile phone.

The impact of source location and human occupancy configurations on in-vehicle SAR levels due to 400 and 900 $\mathrm{MHz}$ on board transmitters was investigated using numerical models by Ruddle (2007; 2009).

The SAR evaluation in the scenarios of passengers using different wireless communication devices inside a vehicle was evaluated by Diao (2013). The effects of the devices with different operational frequencies $900 \mathrm{MHz} / 1.8 \mathrm{GHz} / 2.4 \mathrm{GHz}$, and different seating locations on the SARs were investigated. A simple metal frame was used to simulate the vehicle. A block model for the body and sphere model for the head were used to simulate the human complete body. The generic phone was used in a vertical position and placed in close vicinity to head, but not according to the recommended positions by the IEEE (IEEE-Std. 1528, 2003), i.e., check and tilt.

None of the publications (Anzaldi, 2007; Ruddle, 2007, 2009; Diao, 2013) used a complete realistic car model including all parts, and the mobile phone model was not grabbed by hand and placed in close vicinity to head 
according to IEEE standard (IEEE-Std. 1528, 2003). Moreover, the impact while making a mobile call inside a car on the handset antenna performance was not investigated too.

This paper tries to investigate the EM interaction of a handset antenna and user's head while making a call inside a car. This can be achieved by evaluating the handset antenna performance degradation and the amount of the SAR induced in the user's head. Handset TIS and $\eta_{\text {tot }}$, and induced SAR in the user's head were all evaluated for holding a handset close proximity to head at cheek and tilt-position while making a call inside a complete realistic car model. The numerical calculation is based on Yee-FDTD technique using SEMCAD $X$ version 14.0 Altesch (Schmid \& Partner Eng. AG, 2009).

The reminder of the paper is organized as follow. In Section II, the FDTD-based numerical method is described, In Section III, the design models involved in the numerical computations are styled. In Section IV, the FDTD grid generation needed to realize the study case using FDTD method is given. In Section $\mathrm{V}$, the adopted computation technique results are validated in comparison with previous published work results. In Section VI, the results and implications are illustrated. Section VII discusses the results. Section VIII gives the computational requirements. Finally, section IX concludes the paper.

\section{THE FDTD-BASED NUMERICAL METHOD}

The Finite-Difference Time-Domain (FDTD) method that proposed by Yee (1966) is adopted in this paper as a numerical computation to solve a Maxwell's curl equations in the time domain. Maxwell's curl equations in the time domain are:

$$
\begin{gathered}
\nabla \times \mathbf{E}=-\frac{\partial}{\partial t} \mu \mathbf{H}-\sigma_{H} \mathbf{H} \\
\nabla \times \mathbf{H}=\frac{\partial}{\partial t} \varepsilon \mathbf{E}+\sigma_{E} \mathbf{E} \\
\mathbf{E}=\left(\begin{array}{l}
E_{x} \\
E_{y} \\
E_{z}
\end{array}\right), \quad \mathbf{H}=\left(\begin{array}{l}
\mathrm{H}_{x} \\
H_{y} \\
H_{z}
\end{array}\right)
\end{gathered}
$$

where $\varepsilon$ and $\mu$ are the electric and magnetic properties, of the material, and $\sigma_{\mathrm{E}}$ and $\sigma_{\mathrm{H}}$ are the electric and magnetic conductivity, respectively. Maxwell's curl equations are discretized using a $2^{\text {nd }}$ order finite-difference approximation both in space and in time in an equidistantly spaced mesh (Schmid \& Partner Engineering AG, 2009). The SEMCAD-X simulation platform is selected for simulating the study cases in this work due to its handling, functionality and features for highly detailed CAD models as well as efficient FDTD solver for simulating advanced applications.

\section{Design Models}

\section{A. Handset Design Model}

Different generic phone models were suggested to simulate the mobile phone (IEEE-Std. 1528, 2003; Beard, et al., 2006; Al-Mously and Abousetta, 2008d). The one which suggested by Beard, et al. (2006) and shown in Fig. 1 was adopted and used to simulate the mobile phone handset for the sake of computation technique verification/validation.

Due to the huge amount of FDTD cells needed to simulate a phone call session inside a car, only a working frequency at $1900 \mathrm{MHz}$ that represent the GSM-1900/PCS was used. This $1900 \mathrm{MHz}$ is near the operating frequency of the GSM-1800 MHz. The antenna length is $36 \mathrm{~mm}$ and its square cross section has a $1-\mathrm{mm}$ edge. The monopole is coated by a $1 \mathrm{~mm}$ thick plastic having permittivity $\varepsilon_{y}=2.5$ and electrical conductivity $\sigma=0.005 \mathrm{~S} / \mathrm{m}$. The chassis comprised a PCB, having lateral dimensions of $40 \times 100 \mathrm{~mm}$ and a thickness of $1 \mathrm{~mm}$, symmetrically embedded in a solid plastic case with permittivity $\varepsilon_{\gamma}=4.0$ and electrical conductivity $\sigma=0.04$ $S / \mathrm{m}$, lateral dimensions $42 \times 102 \mathrm{~mm}$, and thickness $21 \mathrm{~mm}$. The antenna is mounted along the chassis centerline so as to avoid differences between right- and left-side head exposure. The antenna is a thick-wire model whose excitation was a $50-\Omega$ sinusoidal voltage source at the gap between the antenna and PCB.

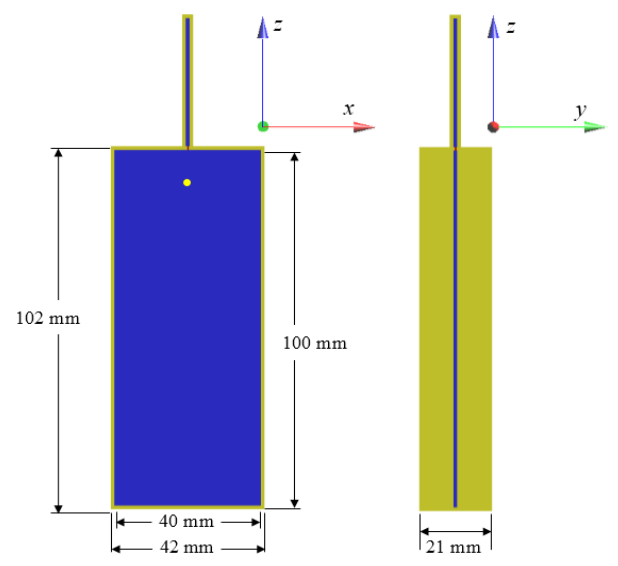

Fig. 1. The CAD model with dimensions of the generic phone used to simulate the mobile phone handset.

\section{B. User's Hand Model}

A semi-realistic hand model consisting of three tissues; skin, muscle and bone (Al-Mously and Abousetta, 2008a; 2009b) was designed and used to simulate the user's hand holding the cellular handset. Table I lists the dielectric properties of the three hand tissues.

\section{User's Head Model}

A Specific Anthropomorphic Mannequin (SAM) developed by different standard committees (IEEE Standard 1528-2003, 2003; IEC 62209-1, 2005) and represents the world-wide standard phantom for compliance testing is used to simulate the human head. The electrical properties of the SAM materials are defined as shown in Table I (IEEE Standard 1528-2003, 2003; IEC 62209-1, 2005; Beard, et al., 2006). 
TABLE I

THE MAIN DIELECTRIC PARTS OF THE HAND AND SAM TISSUES, AND THE CORRESPONDING MATERIAL PARAMETERS

\begin{tabular}{llll}
\hline \hline Hand Tissue & $\varepsilon_{r}$ & $\sigma(\mathrm{S} / \mathrm{m})$ & $\rho\left(\mathrm{kg} / \mathrm{m}^{3}\right)$ \\
\hline Hand skin & 38.714 & 1.2245 & 1100 \\
Hand muscle & 53.418 & 1.3963 & 1041 \\
Hand bone & 11.716 & 0.2924 & 1990 \\
\hline SAM Tissue & $\varepsilon_{r}$ & $\sigma(\mathrm{S} / \mathrm{m})$ & $\rho\left(\mathrm{kg} / \mathrm{m}^{3}\right)$ \\
\hline SAM shell & 5.00 & 0.0016 & 1030 \\
SAM liquid & 40.0 & 1.40 & 1030 \\
\hline \hline
\end{tabular}

\section{Car Model}

A CAD-model for Ferrari F430-brand available with (Schmid \& Partner Engineering AG, 2009) is used to simulate the car. The exact Ferrari F430 measured dimensions are; $4512 \mathrm{~mm}$ (equal to $177.6 \mathrm{in}$ ) length, $1923 \mathrm{~mm}$ (75.7 in) width and $1234 \mathrm{~mm}$ (48.6 inches) height (Ferrari, 2014), whereas, the dimensions of the F430 CAD model are; $4480 \mathrm{~mm}$ length, $1980 \mathrm{~mm}$ width and $1204 \mathrm{~mm}$ height, which are almost the same. Four different materials were recognized in the CAD model to simulate all car-materials; metal, plastic, glass and leather.

Ferrari F430-brand may effect on the mobile phone antenna EM wave radiation like any other sedan automobile, it has been chosen because the Ferrari CAD model is already available commercially. Fig. 2 shows the Ferrari-F430 CAD model.

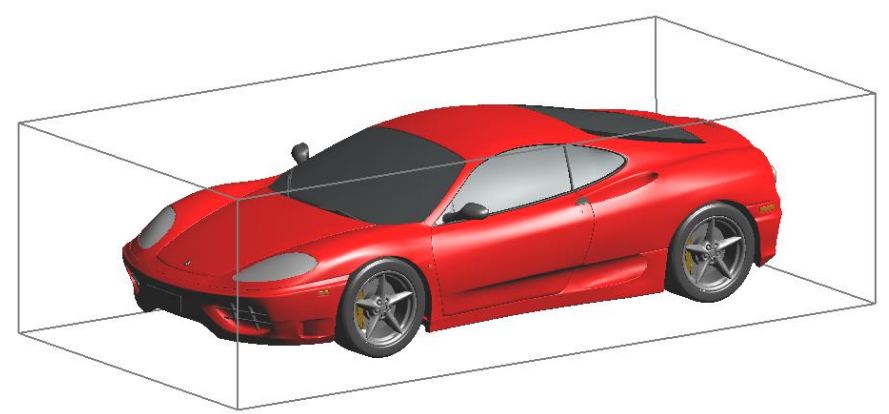

Fig. 2. The CAD model of the Ferrari F430-brand car.

\section{FDTD GRID GENERATION}

Six different scenarios were considered to anticipate the EM interaction of the handset antenna and user's head while setting a mobile call inside a car;

1. Handset, without user's hand, close proximity to head at cheek-position making a mobile call in free-space.

2. Handset, without user's hand, close proximity to head at tilt-position $\left(15^{\circ}\right)$ making a mobile call in free-space.

3. Handset in hand and close proximity to head at checkposition making a mobile call in free space.
4. Handset in hand and close proximity to head at tiltposition making a mobile call in free space.

5. Handset in hand and close proximity to head at checkposition making a mobile call inside a car.

6. Handset in hand and close proximity to head at tiltposition making a mobile call inside a car.

It is important to mention that the procedure for the evaluation of the Electromagnetic (EM) interaction between the mobile phone antenna and human body presented by AlMously (2011b) is adopted and followed in this paper. The FDTD grid cells were aligned in the direction of handset antenna, e.g. the cells are parallel and in the $z$-direction.

\section{A. Grid Generation of the Scenarios 1 and 2}

In these two scenarios a handset close proximity to head at cheek and tilt-position making a mobile call in free-space were set and modeled. The purpose of these two scenarios is to validate the FDTD numerical computation by comparing the achieved results in this paper with the results given by Beard, et al. (2006). A minimum spatial resolution of $1 \times 1 \times 1 \mathrm{~mm}^{3}$ and a maximum spatial resolution of $3 \times 3 \times 3 \mathrm{~mm}^{3}$ in the $x, y$, and $z$ directions are chosen for simulation. The absorbing boundary conditions $(\mathrm{ABCs})$ are set as a uniaxial perfectly matched layer (UPML) mode with a very high strength thickness, where minimum level of absorption at the outer boundary is $(>99.9 \%)$. A grading ratio of 1.2 is used for the solid regions during the simulations. Fig. 3 shows the CAD models of both scenarios.

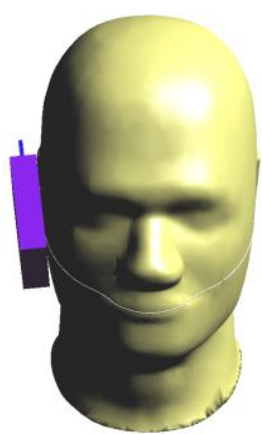

(a)

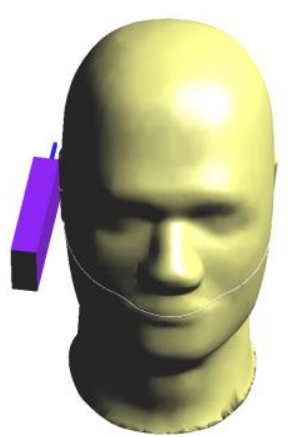

(b)
Fig. 3. The CAD representation of the handset close proximity to head (SAM); (a) at cheek-position and (b) at tilt-position $\left(15^{\circ}\right)$.

\section{B. Grid Generation of the Scenarios 3 and 4}

For the scenarios 3 and 4 , a minimum spatial resolution of $1 \times 1 \times 1 \mathrm{~mm}^{3}$ and a maximum spatial resolution of $3 \times 3 \times 3 \mathrm{~mm}^{3}$ in the $x, y$, and $z$ directions are chosen for simulation. The absorbing boundary conditions (ABCs) are set as a uniaxial perfectly matched layer (UPML) mode with a very high strength thickness, where minimum level of absorption at the outer boundary is (>99.9\%). A grading ratio of 1.2 is used for the solid regions during the simulations. Fig. 4 shows the CAD models of both scenarios. 


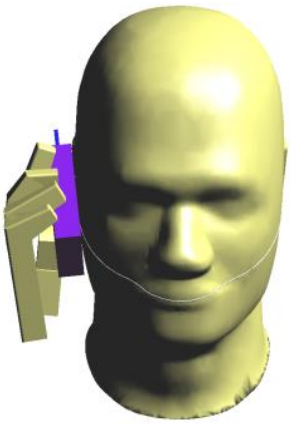

(a)

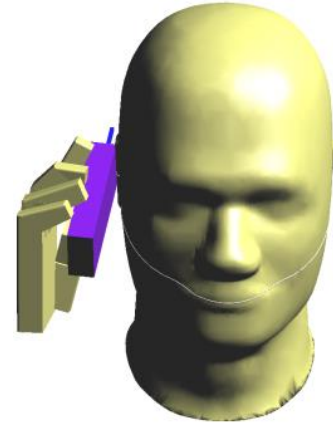

(b)
Fig. 4. The CAD representation of the handset in hand close proximity to head (SAM); (a) at cheek-position and (b) at tilt-position $\left(15^{\circ}\right)$.

\section{Grid Generation of the Scenarios 5 and 6}

For the scenarios 5 and 6 , a minimum spatial resolution of $1 \times 1 \times 1 \mathrm{~mm}^{3}$. The lowest number of cells per wavelength was 4 which gives reasonable results (Dimbylow and Gandhi, 1991). A grading ratio of 1.3 is used for the solid regions during the simulations. Same boundary conditions of Scenario 3 and 4 were used in this scenario. For the six scenarios, a 15 simulation cycles were set to achieve stability.

Fig. 5 shows the CAD models of the scenarios 5 and 6 , whereas, Fig. 6 shows the visualization of voxels after gridding of the scenario 5, where the grid-cells are aligned with handset antenna dimensions, not the car dimensions.

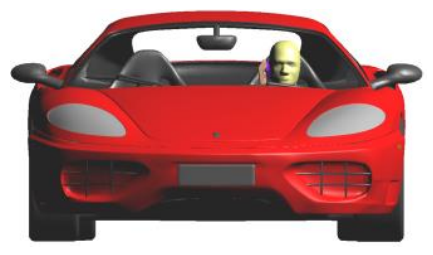

(a)

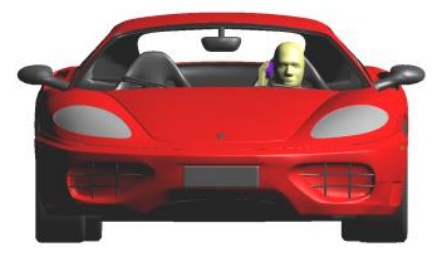

(b)
Fig. 5. The CAD representation of the handset in hand close proximity to head; (a) While making a mobile call inside a car at cheek-position and (b) While making a mobile call inside a car at tilt-position.

Table II lists the total number of FDTD-grid cells required to simulate the handset models in all six scenarios.

TABLE II

THE NuMBER OF GRID CELLS (IN MCELL) GENERATED USING FDTD METHOD FOR THE DIFFERENT SCENARIOS AT $1900 \mathrm{MHZ}$

\begin{tabular}{|c|c|c|}
\hline $\begin{array}{l}\text { Number of FDTD grid cells (Mcell) } \\
\text { with simulation time (hh:mm:ss) }\end{array}$ & $\begin{array}{l}\text { Cheek- } \\
\text { position }\end{array}$ & $\begin{array}{l}\text { Tilt- } \\
\text { position }\end{array}$ \\
\hline $\begin{array}{l}\text { Handset close proximity to head while making a } \\
\text { call in free space, without hand. }\end{array}$ & $\begin{array}{l}2.45522 \\
00: 05: 12\end{array}$ & $\begin{array}{l}2.46208 \\
00: 05: 26\end{array}$ \\
\hline $\begin{array}{l}\text { Handset in hand close proximity to head while } \\
\text { making a call in free space. }\end{array}$ & $\begin{array}{l}3.42624 \\
00: 07: 02\end{array}$ & $\begin{array}{l}3.26771 \\
00: 06: 23\end{array}$ \\
\hline $\begin{array}{l}\text { Handset in hand close proximity to head while } \\
\text { making a call inside a car. }\end{array}$ & $\begin{array}{l}29.7216 \\
02: 17: 00\end{array}$ & $\begin{array}{l}26.576 \\
02: 03: 00\end{array}$ \\
\hline
\end{tabular}

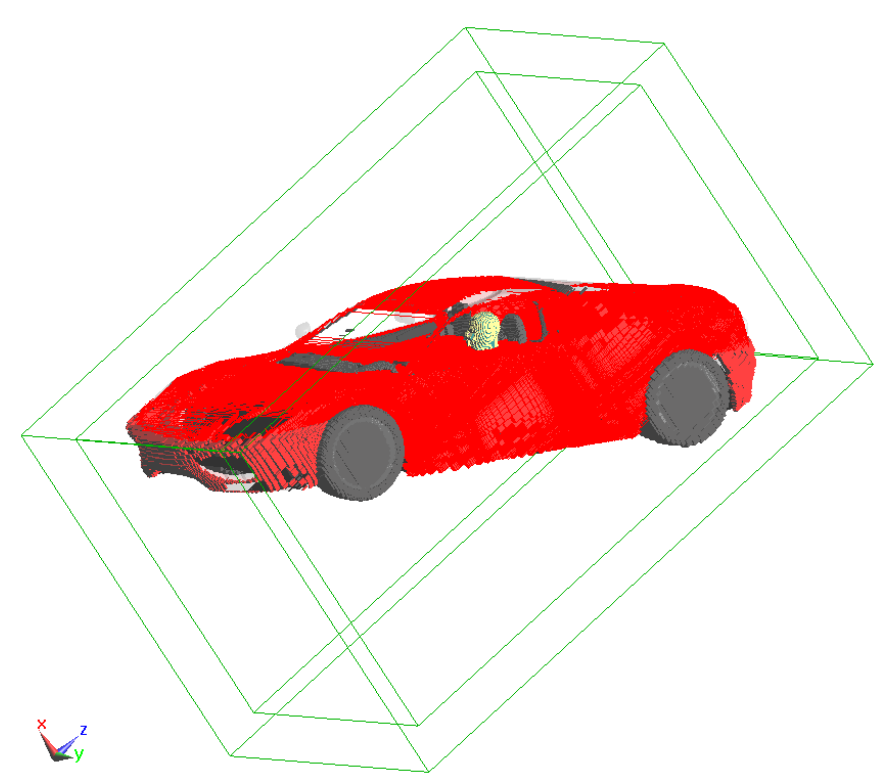

Fig. 6. Visualization of voxels after gridding. Cheek-position and grid of (29.72160) Mcell.

\section{VALIDATION OF THE COMPUTATION TECHNIQUE}

To validate the numerical computation and the FDTDmethod adopted in this paper, a comparison with other published results using a same scenario is essential. The validation of the adopted FDTD computation was achieved by comparing the results of scenarios 1 and 2 with the results given by Beard, et al. (2006) for the same scenarios, where a handset close proximity to head at cheek and tilt-position in free space were modeled as shown in Fig. 3. Table III gives the computed induced SAR in head and the one given by Bread, et al. (2006) for the handset close proximity to head at both cheek and tilt-position with antenna input power of 1.0 Watt. Both results at each position show a good agreement and validate the adopted numerical computations of this paper.

TABLE III

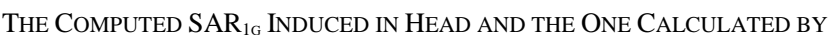
BEARD, ET AL. (2006) FOR THE HANDSET Close PROXIMITY TO HEAD AT CheEK AND TIlt-Position, AND IN FreE-SPACE. Both RESUlts ARE NORMALIZED TO $1 \mathrm{~W}$ INPUT POWER

\begin{tabular}{ll|ll}
\hline \hline & Position & $\begin{array}{l}{ }^{1} \mathrm{SAR}_{1 \mathrm{~g}} \\
(\mathrm{~W} / \mathrm{kg})\end{array}$ & $\begin{array}{c}{ }^{2} \mathrm{SAR}_{1 \mathrm{~g}} \\
(\mathrm{~W} / \mathrm{kg})\end{array}$ \\
\hline $\begin{array}{l}\text { Handset close proximity to head } \\
\text { making a call in free-space (no } \\
\text { hand is involved) }\end{array}$ & $\begin{array}{l}\text { Tilt } \\
\text { heek }\end{array}$ & 11.97 & 11.97 \\
\hline
\end{tabular}

1 The computation obtained by Beard, et al., (2006).

2 The computation obtained in this work.

\section{RESULTS AND IMPLICATIONS}

The impact of in-car mobile phone call on the electromagnetic interaction of the handset antenna and user's head was evaluated from two different perspectives; first, the 
antenna performance, second, the specific absorption rate (SAR) induced in the user's head

The antenna performance represented by the antenna total efficiency $\left(\eta_{\text {tot }}\right)$, total radiated power $(T R P)$ and total isotropic sensitivity $(T I S)$. Both TRP and $\eta_{\text {tot }}$ are defined as follow (Balanis, 1997);

$$
\begin{gathered}
T R P=\eta_{\text {tot }} \times \text { input power } \\
\eta_{\text {tot }}=\eta_{\text {rad }} \times \eta_{\text {mis }}
\end{gathered}
$$

where $\left(\eta_{\text {rad }}\right)$ is the radiation efficiency and $\left(\eta_{\text {mis }}\right)$ is the mismatch efficiency.

The TIS is a measure of the handset receiving performance, where both TIS and TRP together determine the effectiveness of the handset as a piece of radio equipment, in particular the maximum range at which the handset can operate from the base station with some given level of performance (Chen, 2007).

The specific absorption rate (SAR) induced in the user's head is an index that quantifies the rate of energy absorption in biological tissue expressed in watts per kilogram (W/kg). SAR is generally quoted as a figure averaged over a volume corresponding to either $1 \mathrm{~g}$ or $10 \mathrm{~g}$ of body tissue. Based on SCC-34, SC-2, WG-2 - Computational Dosimetry, IEEE-Std. 1529 IEEE Standard-1529, draft), an algorithm has been implemented using a FDTD-based EM simulator, SEMCAD X (Schmid \& Partner Engineering AG, 2009).

The handset in all six scenarios is modeled with operating frequency of $1900 \mathrm{MHz}$ and antenna input power of $125 \mathrm{~mW}$.

The antenna performance parameters $\eta_{\text {mis }}, \eta_{\text {rad }}$ and $\eta_{\text {tot }}$ given for the handset making a call in free space, making a call while in hand close to head in free space and making a call while in hand close to head inside a car are all listed in Table IV, whereas, the total radiated power (TRP), TIS and induced SAR (averaged over $1 \mathrm{~g}$ ) in head values are listed in Table V.

TABLE IV

\begin{tabular}{|c|c|c|c|c|}
\hline & & $\eta_{\text {mis }} \%$ & $\eta_{\text {rad }} \%$ & $\eta_{\text {tot }} \%$ \\
\hline \multicolumn{2}{|l|}{ Handset with a call in free-space } & 88.07 & 92.33 & 81.32 \\
\hline \multirow{2}{*}{$\begin{array}{l}\text { Handset in hand close } \\
\text { proximity to head while } \\
\text { making a call in free space }\end{array}$} & & 89.26 & 24.89 & 22.21 \\
\hline & Tilt & 96.50 & 23.78 & 22.95 \\
\hline \multirow{2}{*}{$\begin{array}{l}\text { Handset in hand close } \\
\text { proximity to head while } \\
\text { making a call inside a car }\end{array}$} & Cheek & 80.75 & 0.844 & 0.682 \\
\hline & Tilt & 47.77 & 1.112 & 0.532 \\
\hline
\end{tabular}

THE ANTENNA EFFICIENCIES OF THE HANDSET IN DIFFERENT SCENARIOS

The values of the induced $\mathrm{SAR}_{1 \mathrm{~g}}$ in head for both cheek and tilt positions and listed in Table $\mathrm{V}$ are almost under the limit of the IEEE/ANSI/FCC (IEEE-Std. C95.1b, 2004; IEEE Standard-1529, draft), where the maximum is $1.6(\mathrm{~W} / \mathrm{kg})$ averaged over $1 \mathrm{~g}$.

Fig. 7 illustrates the 3D electrical far-field radiation pattern of the handset in hand close proximity to head at cheekposition while making a call in free-space. The same radiation pattern is illustrated in Fig. 8, but for the handset at tiltposition.

TABLE V

THE ANTENNA TRP AND TIS OF THE HANDSET AT DIFFERENT SCENARIOS

\begin{tabular}{|c|c|c|c|c|}
\hline & & $\begin{array}{l}\text { TRP } \\
\mathrm{mW}\end{array}$ & $\begin{array}{l}\text { TIS } \\
\mathrm{dBm}\end{array}$ & $\begin{array}{l}\mathrm{SAR}_{1 \mathrm{~g}} \\
\mathrm{~W} / \mathrm{kg}\end{array}$ \\
\hline \multicolumn{2}{|l|}{ Handset with a call in free-space } & 101.65 & -105 & na \\
\hline \multirow{2}{*}{$\begin{array}{l}\text { Handset in hand close } \\
\text { proximity to head while } \\
\text { making a call in free space }\end{array}$} & Cheek & 27.00 & -99.48 & 1.06 \\
\hline & Tilt & 28.69 & -99.63 & 1.63 \\
\hline \multirow{2}{*}{$\begin{array}{l}\text { Handset in hand close } \\
\text { proximity to head while } \\
\text { making a call inside a car }\end{array}$} & Cheek & 0.85 & -84.36 & 1.06 \\
\hline & Tilt & 0.66 & -83.27 & 1.68 \\
\hline
\end{tabular}
WITH THE CORRESPONDING SAR ${ }_{1 \mathrm{G}}$ INDUCED IN HEAD AT $1900 \mathrm{MHZ}$
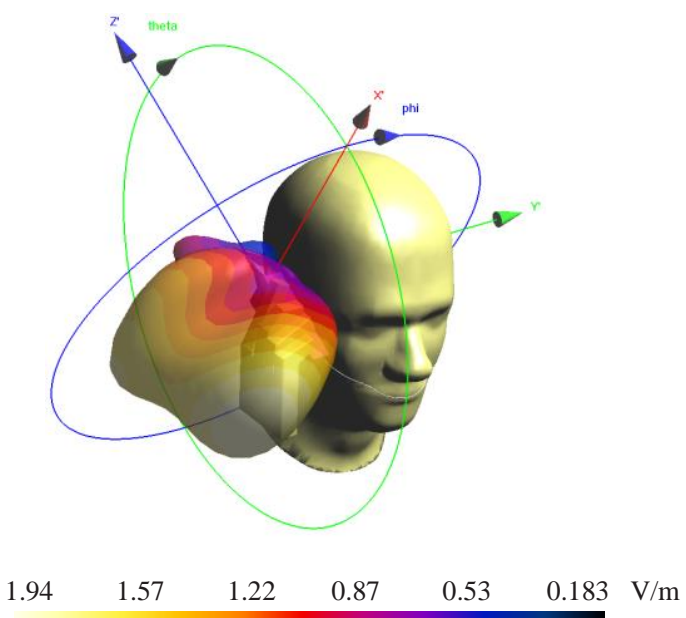

Fig. 7. The three-dimensional electrical far-field radiation pattern of the handset in hand close to head at cheek-position while making a call in freespace.

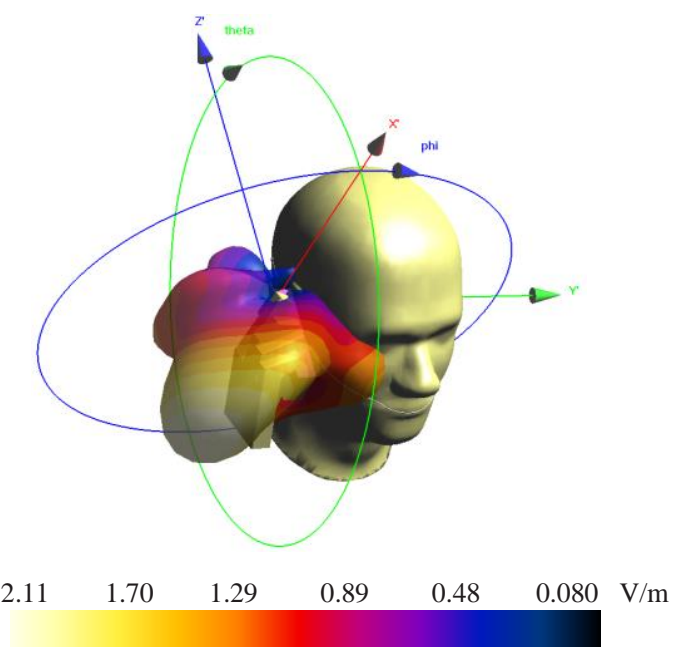

Fig. 8. The three-dimensional electrical far-field radiation pattern of the handset in hand close to head at tilt-position while making a call in free-space. 
Fig. 9-a shows the surface distribution of the spatial peak SAR [IEEE-1529] for the handset in hand close proximity to head at cheek-position while making a call inside a car. Fig. 9b shows the same distribution at cheek-position with zoomed head view, whereas, Fig. 9-c shows the same distribution at tilt-position.

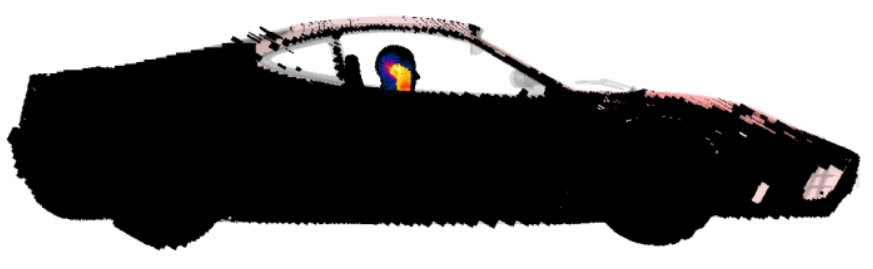

(a)

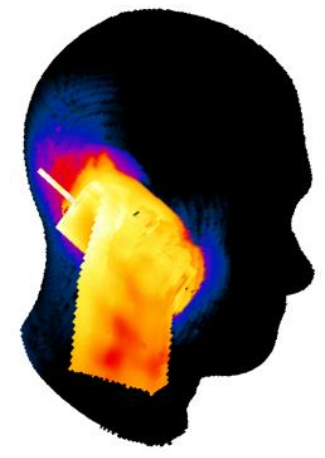

(b)

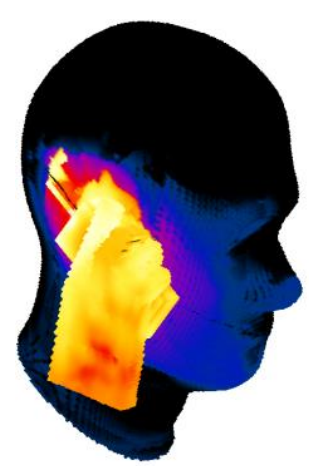

(c)
Fig. 9. The spatial peak SAR [IEEE-1529] surface distribution for the handset in hand close proximity to head at cheek-position while making a call inside a car, (b) the same surface distribution for the zoomed head at cheek-position, and (c) the same surface distribution for the zoomed head at tilt-position.

Fig. 10 shows the handset in hand close proximity to head inside a car with $x, y, z$ axis and theta and phi directions to illustrate the 3D far-field radiation patterns of the handset inside a car while making a mobile call at cheek and tiltposition, Fig. 11 and Fig. 12, respectively.

The 3D electrical far-field radiation pattern of the handset inside a car at cheek-position, Fig. 11, shows a dramatic radiation pattern change, as compared with the patterns of Fig. 7 and Fig. 8. The main lobe is the direction of the car roof due to the ground effect with minor lobes in the left-side direction of the driver, whereas, Fig. 12 shows two main lobes, one in the direction of the car roof and the other in the left-side direction of the driver due to tilting the handset $15^{\circ}$ with respect to head

\section{DISCUSSION}

\section{A. Unsuccessful Mobile Call Establishment inside a Car}

The results given in Table IV shows a high degradation in the antenna performance, i.e., $\eta_{\text {tot }}$, of the handset in hand close proximity to head while making a mobile call inside a car, as compared with the case in free space. A degradation of $(-96.9 \%)$ at cheek-position and $(-97.7 \%)$ at tilt-position are observed. This is mainly due to the degradation in the $\eta_{\text {rad }}$ because of the car body coverage, and degradation in the $\eta_{\text {mis }}$, as well. Although the presence of head at both positions in free space degrades the antenna $\eta_{\text {rad }}$ but at the same time it improves the antenna $\eta_{\text {mis }}$, Table IV. On the other hand, this improvement turns oppositely when the antenna is placed close to head and directly under the car metal roof, especially at tilt position where the antenna is closer to head. (-9.5\%) degradation in the antenna $\eta_{\text {mis }}$ at cheek position was noticed, whereas, a (-50.5\%) degradation was at tilt position.

The same scenario of degradation was observed, Table V, for the TIS while making a mobile call inside a car, as compared with the call in free space. A degradation of $(-15.2 \%)$ and $(-16.4 \%)$ was computed for the cheek and tiltposition, respectively. It is obvious that the presence of car shows more negative impact on the handset antenna performance at tilt-position, as compared with the case at cheek-position. The same effect is applicable for the TRP, Table V, since TRP depends directly on the $\eta_{\text {tot }},(4)$.

Table V shows that the induced $\mathrm{SAR}_{1 \mathrm{~g}}$ in the user's head at tilt-position is more than at cheek-position, while making a call in free-space. These results are in consistence with the results presented by Al-Mously and Abousetta (2008b).

Since the $\mathrm{SAR}_{1 \mathrm{~g}}$ induced in the user's head depends on the handset antenna near field, not the far field radiation, the multi reflections of the handset EM waves inside a car should have no effect on the amount of the induced $\mathrm{SAR}_{1 \mathrm{~g}}$. For the same antenna input power $(125 \mathrm{~mW})$ of the handset making a call in free-space and inside a car, as well, no change in the $\mathrm{SAR}_{1 \mathrm{~g}}$ values were noticed due to the presence of car, as shown in Table V.

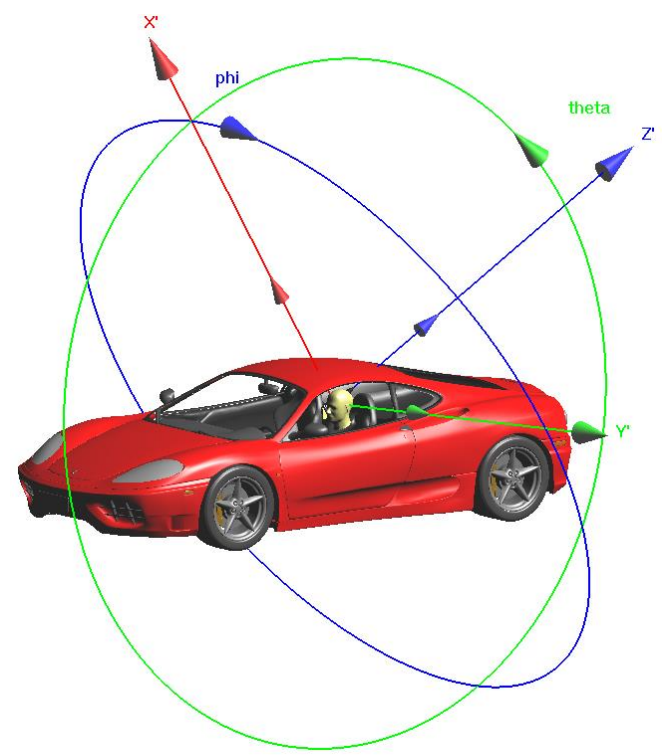

Fig. 10. The CAD model of the handset in hand close proximity to head inside a car with $x, y, z$ axis and theta and phi directions. 

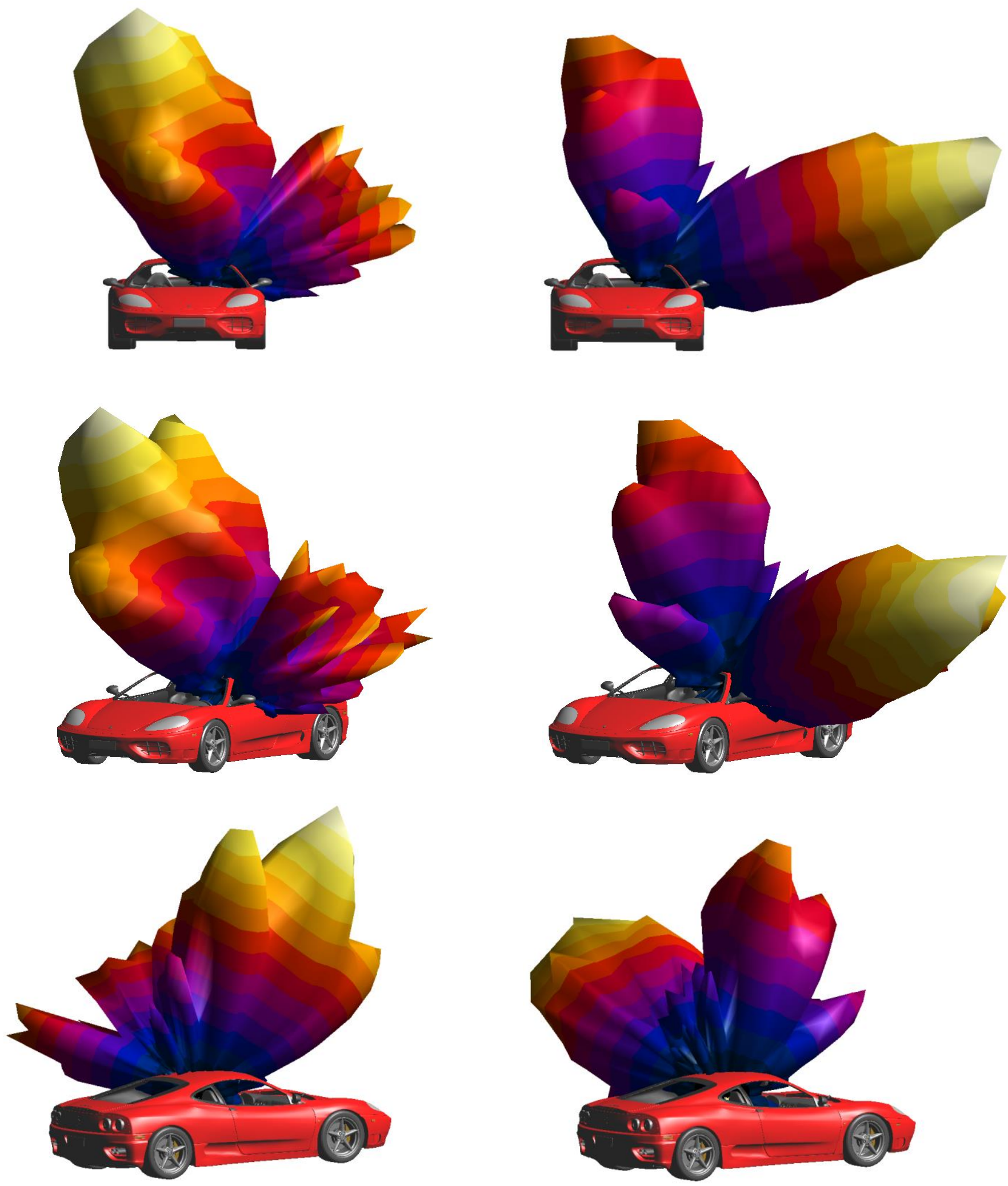

0.58

$$
\begin{array}{llllll}
0.46 & 0.35 & 0.23 & 0.12 & 0.001 & \mathrm{~V} / \mathrm{m}
\end{array}
$$

0.66

0.53

0.40

0.26

0.13

$0.001 \mathrm{~V} / \mathrm{m}$

Fig. 11. Different views of the 3D total electric radiation pattern of the handset in hand close proximity to head at cheek-position while making a mobile call inside a car.
Fig. 12. Different views of the 3D total electric radiation pattern of the handset in hand close proximity to head at tilt-position while making a mobile call inside a car. 
According to (4) and with antenna TIP of $125 \mathrm{~mW}$, the antenna TRP is $0.85 \mathrm{~mW}$ for the handset at check-position and $0.66 \mathrm{~mW}$ for the handset at tilt-position, while making a mobile call inside a car, Table VI. These TRPs are not enough to establish a successful call with the mobile base-station antenna, The mobile base-station needs a minimum of $1 \mathrm{~mW}$ $(0.0 \mathrm{~dB})$, power level number 15 , to be connected successfully with the handset terminal (Poole, 2004).

The recommended minimum accepted degradation in TIS while making a mobile call, as compared with the mobile call in free-space, neither hand nor head proximity exists, is about 10-12 dBm (Lindberg, 2007; Al-Mously and Abousetta, 2009a). This recommendation does exists with the handset while making a call in free-space, but does not exists while making a mobile call inside a car, Table V. Moreover, the recommended minimum accepted TIS for the GSM family is (92.4 - 99.4) dBm, based on frequency (Pedersen, 2012), regardless the handset position or the object in close proximity. Also, this recommendation does exists with the handset while making a call in free-space, but does not exists while making a mobile call inside a car, where the TIS values are -84.36 and -83.27 for cheek and tilt-position with degradation of $-20.64 \mathrm{dBm}$ and $-21.73 \mathrm{dBm}$, respectively, Table V.

Therefore, the unaffected safely $\mathrm{SAR}_{1 \mathrm{~g}}$ values that given in Table $\mathrm{V}$ due to the presence of car are considered not realistic and do not reflect the actual values, as long as a successful connection between the handset of such a scenario with a mobile base-station cannot be established due to low TRP.

\section{B. Successful Mobile Call Establishment inside a Car}

As mentioned above, the establishment of a successful call between the handset and mobile base-station necessitates a TRP of more than $1 \mathrm{~mW}$. Based on the TRP values given in Table $\mathrm{V}$, for the handset making a call inside a car, the mobile base-station sends a signal to handset requests for increasing the antenna output power which consequently increases TIP. Table VI shows that the increments of $17.6 \%$ and $51.5 \%$ in the $T R P$, for cheek and tilt-position, respectively, are required to achieve the minimum value of $1 \mathrm{~mW}$. These increments necessitate a corresponding increments in the TIP. TIPs of $147.1 \mathrm{~mW}$ and $189.4 \mathrm{~mW}$ are looked-for to achieve a successful mobile call.

TABLE VI

THE ACTUAL TRP AND LOOKED-FOR TIP VALUES FOR THE HANDSET IN SCENARIOS 5 AND 6

\begin{tabular}{ll|llll}
\hline \hline & & $\begin{array}{c}{ }^{1} \text { TRP } \\
\mathrm{mW}\end{array}$ & $\begin{array}{c}{ }^{2} \text { TRP } \\
\mathrm{mW}\end{array}$ & $\begin{array}{c}{ }^{3} \text { Incr. } \\
\%\end{array}$ & $\begin{array}{c}{ }^{4} \text { TIP } \\
\mathrm{mW}\end{array}$ \\
\hline $\begin{array}{l}\text { Handset in hand } \\
\text { close proximity to } \\
\text { head while making a } \\
\text { call inside a car }\end{array}$ & Tilt & 0.66 & 1.00 & 51.5 & 189.4 \\
\hline \hline
\end{tabular}

1 The actual TRP that establishes an unsuccessful mobile call.

2 The minimum TRP required to establish a successful mobile call.

3 Increment percent in TRP to establish a successful mobile call.

4 The looked-for corresponding TIP for a successful mobile call.
With these new TIP values, which represent the minimum looked-for values and able to establish a successful mobile call, the numerical computation of the scenarios 5 and 6 were scaled accordingly, since the SAR is directly proportional with the input power. The handset antenna TIP is set to equal 147.1 $\mathrm{mW}$ for the scenario 5 and $189.4 \mathrm{~mW}$ for the scenario 6 , instead of the $125 \mathrm{~mW}$ for both. The corresponding new TRP and $\mathrm{SAR}_{1 \mathrm{~g}}$ values were achieved and listed in Table VII. The numerical computation shows TRP of $1 \mathrm{~mW}$ for both scenario, 5 and 6. Thus the corresponding SAR values induced in the user's head can be considered realistic as long as with such $T I P$ and TRP values a mobile call between the mobile basestation and the handset terminal can be established successfully.

TABLE VII

THE MINIMUM LOOKED-FOR TIP VALUES FOR ESTABLISHING A SUCCESSFUL Mobile CALl INSIDE A CAR AND THE CORRESPONDING TRP AND SAR VALUES AT DIFFERENT POSITIONS.

\begin{tabular}{ll|lll}
\hline \hline & & $\begin{array}{l}{ }^{1} \text { TIP } \\
\mathrm{mW}\end{array}$ & $\begin{array}{l}\text { TRP } \\
\mathrm{mW}\end{array}$ & $\begin{array}{l}\mathrm{SAR}_{1 \mathrm{~g}} \\
\mathrm{~W} / \mathrm{kg}\end{array}$ \\
\hline $\begin{array}{l}\text { Handset in hand close Cheek } \\
\text { proximity to head while } \\
\text { making a call inside a car }\end{array}$ & 147.1 & 1.00 & 1.25 \\
\hline \hline
\end{tabular}

1 The minimum looked-for TIP corresponding to a successful mobile call.

It is very clear in Table VII that establishing a successful mobile call inside a car which necessitates a TIP increment that consequently leads to increase the induced $\mathrm{SAR}_{1 \mathrm{~g}}$ in head by percent values of $17.6 \%$ and $51.5 \%$ at cheek and tiltposition, respectively. Due to this increase, the $\mathrm{SAR}_{1 \mathrm{~g}}$ may cross the IEEE/ANSI/FCC limits as in the case of tilt-position, $2.54 \mathrm{~W} / \mathrm{kg}$.

\section{COMPUTATIONAL REQUIREMENTS}

All computations were performed on a CPU of $2.4 \mathrm{GHz}$ Intel ${ }^{\circledR}$ core $^{\mathrm{TM}}$ i7 Laptop machine (Dell, XPS L702X) with 8 GB memory and 64-bit Windows operating system. No hardware accelerator aXware (Schmid \& Partner Engineering AG, 2009) was used to accelerate the simulations. The number of FDTD grid cells and running time were totally depend on the problem size.

\section{CONCLUSION}

In addition to the continuous calling of the national transportation safety boards and agencies in most countries for a complete ban on talking by mobile phone while driving, due to the possible car accidents, this paper showed a possible biological hazard of the mobile call inside a car or while driving owing to the induced SAR in head tissues. The results achieved throughout this paper showed a significant degradation in the handset antenna performance, i.e., total isotropic sensitivity and total efficiency, while making a 
mobile call inside a car. This degradation may not initiate the handset to establish a successful mobile call and consequently the mobile base-station may request the handset to increases its input power. Accordingly, this will certainly increases the induced SAR in head. The numerical computations showed a $17.6 \%$ and $51.5 \%$ increase in the spatial peak $\mathrm{SAR}_{\mathrm{gg}}$ induced in the head tissues for the handset at cheek and tilt-position, respectively, while making a mobile call inside a car, as compared with the mobile call in free space. In other words, making a mobile phone call inside a car is more hazardous than a mobile call in free space and the $\mathrm{SAR}_{1 \mathrm{~g}}$ induced in head tissues may cross the IEEE/ANSI/FCC standard limits.

\section{REFERENCES}

Abousetta, M.M., Alhamdani, Z.K., Al-Mously, S.I., Al-Daghistani, M.E. and Omran, K.F., 1999. Electromagnetic hazard mitigation in mobile telephones. In: IEE, Seminar on electromagnetic assessment and antenna design relating to health implications of mobile phones (Ref. No. 1999/043), June 1999. London, UK.

Al-Mously, S.I., 2011a. Factors influencing the EM interaction between mobile phone antennas and human head. Digital Information and Communication Technology and its Applications Communications in Computer and Information Science, 166, pp.106-120.

Al-Mously, S.I, 2011b. Assessment procedure of the EM Interaction between mobile phone antennae and human body. International Journal on New Computer Architectures and Their Applications (IJNCAA), 1(1), pp.1-14.

Al-Mously, S.I., 2012a. Mobile phone EMC deterioration due to different realistic usage patterns. In: PIER, Progress in electromagnetics research symposium, August 2012. Moscow, Russia.

Al-Mously, S.I, 2012b. Cellular handset antennas design, performance enhancement, and assessment of their EM interaction with a human, $1^{\text {st }} \mathrm{ed}$. LAP Lambert Academic Publishing, ISBN: 978-3-8473-0403-6

Al-Mously, S.I. and Abdalla, A.Z., 2009. Hand implications on the coupling between human head and different cellular phones. In: TELSIKS, 9th International conference on telecommunication in modern satellite, cable, and broadcasting services, 7-9 Oct. 2009. Serbia, Belgrade.

Al-Mously, S.I. and Abousetta, M.M., 2008a. A novel cellular handset design for an enhanced antenna performance and a reduced SAR in the human head, International Journal of Antennas and Propagation, 10 pages. doi:10.1155/2008/642572

Al-Mously, S.I. and Abousetta, M.M., 2008b. Anticipated impact of handhold position on the electromagnetic interaction of different antenna types/positions and a Human in cellular communications, International Journal of Antennas and Propagation, 22 pages. doi:10.1155/2008/102759

Al-Mously, S.I. and Abousetta, M.M., 2008c. A Study of the Hand-Hold Impact on the EM Interaction of a Cellular Handset and a Human, International Journal of Electronics, Circuits and Systems , 2(2), pp.91-95.

Al-Mously, S.I. and Abousetta, M.M., 2008d. Study of both antenna and PCB positions effect on the coupling between the cellular hand-set and human head at GSM-900 standard. In: iWAT2008, The international workshop on antenna technology, 4-6 March 2008. Chiba University, Japan.

Al-Mously, S.I. and Abousetta, M.M., 2009a. User's Hand Effect on TIS of Different GSM900/1800 Mobile Phone Models Using FDTD Method, World Academy of Science, Engineering and Technology, 3(1), pp.830-835.

Al-Mously, S.I. and Abousetta, M.M., 2009b. Cell Phones: The EM coupling with human body, $1^{\text {st }}$ ed. VDM Publishing House Ltd., ISBN: 978-3-63921871-8.

Anzaldi, G., Silva, F., Fernandez, M. and Quilez, M., Riu, P.J., 2007. Initial analysis of SAR from a cell phone inside a vehicle by numerical computation. IEEE Transactions on Biomedical Engineering, 54(5), pp.921-930.
Balanis, A., 1997. Antenna theory: Analysis and design, John Wiley and Sons.

Beard, B., Kainz, W., Onishi, T., Iyama, T., Watanabe, S., Fujiwara, O., Wang, J., Bit-Babik, G. Faraone, A., Wiart, J., Christ, A., Kuster, N., Lee, A., Kroeze, H., Siegbahn, M., Keshvari, J., Abrishamkar, H., Simon, W., Manteuffel, D. and Nikoloski, N., 2006. Comparisons of computed mobile phone induced SAR in the SAM phantom to that in anatomically correct models of the human head, IEEE Transaction on Electromagnetic Compatibility, 48(2), pp.397-407.

Chavannes, N., Futter, P., Tay, R., Pokovic, K. and Kuster, N., 2006. Reliable prediction of mobile phone performance for different daily usage patterns using the FDTD method. In: IEEE, The international workshop on antenna technology (IWAT 2006). White Plains, NY, USA.

Chen, Z.N., 2007. Antennas for portable devices, John Wiley \& Sons, Ltd, Chichaster.

Diao, Y., Sun, W.N., Hung Chan, K.H., Leung, S.W. and Siu, Y.M., 2013. SAR evaluation for multiple wireless communication devices inside a vehicle. In: URSI, The international symposium on electromagnetic theory (EMTS), 20-24 May 2013. Hiroshima, Japan.

Dimbylow, P.J. and Gandhi, O.P., 1991. Finite-difference time-domain calculations of SAR in a realistic heterogeneous model of the head for planewave exposure from $600 \mathrm{MHz}$ to $3 \mathrm{GHz}$, Physics in Medicine and Biology, (6), pp.1075-1089.

Dimbylow, P.J., and Mann, S.M., 1994. SAR calculations in an anatomically realistic model of the head for mobile communication transceivers at 900 MHz and $1.8 \mathrm{GHz}$, Phys. Med. Biol., (39), pp.1537-1553.

Ferrari, 2014. Overview; Ferrari Spider F430. [online] Available at: <http://auto.ferrari.com/en_EN/sports-cars-models/past-models/f430-spider/> [Accessed 25 June 2014].

Francavilla, M., Schiavoni, A., Bertotto, P., Richiardi, G., 2001. Effect of the hand on cellular phone radiation, IEE Proceeding of Microwaves, Antennas and Propagation, 148, pp.247-253.

Futter, P., Chavannes, N., Tay, R., et al., 2008. Reliable prediction of mobile phone performance for realistic in-use conditions using the FDTD method, IEEE Antennas and Propagation Magazine, 50(1), pp. 87-96.

Gandhi, O.P., Lazzi, G. and Furse, C.M., 1996. Electromagnetic absorption in the human head and neck for mobile telephones at 835 and $1900 \mathrm{MHz}$. IEEE Transaction on Microwave Theory and Techniques, 44(10), pp.1884,1897.

IEC Standard, 2005, 62209-1 Human exposure to radio frequency fields from hand-held and body-mounted wireless communication devices-human models, instrumentation, and procedures - part 1: Procedure to determine the specific absorption rate (SAR) for hand-held devices used in close proximity to the ear (frequency range of $300 \mathrm{MHz}$ to $3 \mathrm{GHz}$ ).

IEEE Standard, 2003. 1528-2003 Recommended practice for determining the peak spatial-average specific absorption rate (SAR) in the human head from wireless communications devices: measurement techniques.

IEEE Standard, 1529 Recommended practice for determining the peak spatialaverage specific absorption rate (SAR) associated with the use of wireless handsets - computational techniques," draft standard.

Jensen, M.A. and Rahmat-Samii, Y., 1995. EM interaction of handset antennas and a human in personal communications. Proceeding of the IEEE, 83(1), pp.7-17.

Kouveliotis, N.K., Panagiotou, S.C., Varlamos, P.K. and Capsalis, C.N., 2006. Theoretical Approach of the Interaction Between a Human Head Model and a Mobile Handset Helical Antenna Using Numerical Methods, Progress In Electromagnetics Research, PIER 65, pp.309-327.

Lindberg, P., 2007. Wideband active and passive antenna solutions for handheld terminals, Ph. D. Uppsala University.

Pedersen, G.F., 2012. Limit values for downlink mobile telephony in Denmark. Aalborg University. [pdf] Aalborg University.

http://vbn.aau.dk/files/75767053/Limit_values_for_Downlink_Mobile_Teleph ony_in_Denmark.pdf [Accessed 20 May 2014]. 
Poole, I., 2004. Radio-Electronics.com; resources and analysis of electronics engineers. [online] Available at: <http://www.radio-electronics.com/info/ cellulartelecomms/gsm_technical/power-control-classes-amplifier.php> [Accessed 20 May 2014].

Ruddle, AR., 2007. Computed SAR distributions for the occupants of a car with a $400 \mathrm{MHz}$ transmitter on the rear seat. In: EMCZUR, 18th International Zurich symposium on electromagnetic compatibility, September 2007. Munich, Germany.

Ruddle, AR., 2009. Computed SAR levels in vehicle occupants due to onboard transmissions at $900 \mathrm{MHz}$. In: Antennas \& propagation conference, 1617 November 2009. Loughborough, UK.

SEMCAD-X, 2009. Version 14.0 Altesch. Reference Manual, Simulation Platform for Electromagnetic Compatibility, Antenna Design and Dosimetry, SPEAG - Schmid \& Partner Engineering AG: 〈http://www.semcad.com>.
Toftgard, J., Hornsleth, S.N. and Andersen, J.B., 1993. Effects on portable antennas of the presence of a person, IEEE Transaction on Antennas and Propagation, 41(6), pp.739-746.

Wang, J. and Fujiwara, O., 2003, Comparison and evaluation of electromagnetic absorption characteristics in realistic human head models of adult and children for $900-\mathrm{MHz}$ mobile telephones. IEEE Transaction on Microwave Theory and Techniques, 51(3), pp.966-971.

Watanabe, S.-I., Taki, M., Nojima, T. and Fujiwara, O., 1996. Characteristics of the SAR distributions in a head exposed to electromagnetic field radiated by a hand-held portable radio. IEEE Transaction on Microwave Theory and Techniques, 44(10), pp.1874-1883.

Yee, K.S., 1966. Numerical Solution of Initial Boundary Value Problems Involving Maxwell's Equations in Isotropic Media. IEEE Transaction on Antennas and Propagation, 14(3), pp.302-307. 